Fourth International Conference on Sustainable Construction Materials and Technologies http://www.claisse.info/Proceedings.htm

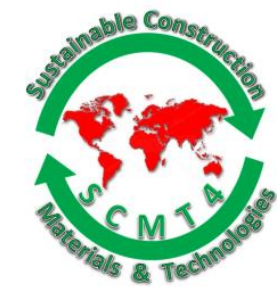

SCMT4

Las Vegas, USA, August 7-11, 2016

\title{
Strength and Water Resistance of Low-Grade Fly Ash Incorporated Magnesia-Phosphate Cement Based Materials
}

\author{
Hongyan $\mathrm{Ma}^{1}$, and Yan Huang ${ }^{2}$ \\ ${ }^{1}$ Department of Civil, Architectural and Environmental Engineering, Missouri University of Science and \\ Technology, Rolla, MO 65401, US. Email: <mahon@mst.edu> \\ ${ }^{2}$ Department of Civil and Environmental Engineering, the Hong Kong University of Science and \\ Technology, Hong Kong SAR, CHINA. Email: <yhuangbj@connect.ust.hk>
}

\begin{abstract}
Developed countries are suffering from aging/deterioration of infrastructure, and repair/rehabilitation is thus a long-term work. Magnesia-phosphate cement (MPC) is a promising binder material for utilization in repair works of degraded infrastructure. However, the cost of MPC is much higher than normally used cementitious materials. The incorporation of industrial wastes, such as low-grade fly ash which is not suitable for use as supplementary cementitious materials, can largely reduce the material cost of MPC and make the color of the resulting material consistent with the substrate. It will be a surprise if specific properties can be improved. In this paper, an MPC paste with the magnesia-to-phosphate molar (M/P) ratio of 8 and the water-to-solid (W/S) ratio of 0.2 is selected as the reference, and a low-grade fly ash is used to replace $20 \%, 40 \%$ and $60 \%$ of the solid phase by volume, respectively. The compressive strengths of the four pastes are measured following the increasing ages, and the water resistance indices of them are also evaluated. The results show that the higher the fly ash replacement, the lower the compressive strength at all ages, but the better the long-term water-resistance. Based on a three-limit theory, the effect of fly ash replacement on compressive strength is explained, and it is proved that the fly ash is more than an inert filler. The influence of fly ash on water resistance is also explained through a microstructural analysis.
\end{abstract}

\section{INTRODUCTION}

Since Portland cement was patented over 180 years ago, it has become the dominant binder used in contemporary concrete. Annual worldwide Portland cement production is currently around $3 \mathrm{G}$ tonne [Juenger et al. 2011]. The construction materials industry is under increasing pressure to reduce the energy used in the production of Portland cement and the associated greenhouse gas emission, not to mention the fact that Portland cement is not the perfect binder for all construction applications due to its relatively slow setting and deterioration in aggressive environments. There is thus a burgeoning interest in the development of alternatives to Portland cement as a binder (or cementitious material) for concrete. Meanwhile, developed countries have been suffering from aging and deterioration of their infrastructure, which has been bringing huge economic lost every year. According to the latest report card published by ASCE, America's cumulative GPA for infrastructure was D+ in 2013 [ASCE 2013]. Actually, the grades have been near failing since 1998, due to delayed maintenance and underinvestment over most of the infrastructure categories, and the estimated investment needed by 2020 to improve the grades will be $\$ 3.6$ trillion [ASCE 2013]. Repair/rehabilitation will thus be a long-term work for civil engineering professionals. 
Magnesia-phosphate cements (MPCs) are relatively new alternatives to Portland cement. They can set very quickly at low temperature and produce high strength patches with low permeability and little shrinkage [Seehra et al. 1993; Yang et al. 2000], and are also termed chemically bonded ceramics [Ma et al. 2014a]. MPCs may not entirely replace Portland cement, but they are more suitable for particular applications, especially in the fields of structural repair and cold weather construction, due to their advantages. Lowgrade or by-product magnesia have been used to make rapid repair materials for pavements and reinforced structures [Formosa et al. 2012; Qiao et al. 2010]. Limited study have shown that replacing half of the solid components in magnesia-phosphate cement by fly ash can reduce the cost and carbon footprint of this material not only, but also appropriately improve the service properties [Ding and $\mathrm{Li}$ 2005]. This gives the material, fly ash incorporated magnesia-phosphate cement (FA-MPC), the potential to be used as a largescale construction material. It's worth noting that unlike geopolymers and Portland cement concrete, in which fly ash is required to have relatively high glass content and the composition variation of fly ash results in performance variation of the resulting materials [Provis et al. 2012], the required degree of reaction of fly ash in FA-MPC is very low [Ding and Li 2005]. Thus low-grade fly ash (high carbon content and low glass content), that can hardly be used to make geopolymers and concrete, is possible to be consumed in making FA-MPC, which undoubtedly bring additional environmental benefit.

The effects of low-grade fly ash on properties of MPC are investigated in this paper. A magnesium potassium phosphate cement (MKPC), which is a member of the MPCs family, is taken as the reference, and a low-grade fly ash is used to partially replace the solid components of the MKPC by volume. The compressive strengths of different pastes are measured following the increasing ages, and the water resistance indices of them are also evaluated. The mechanisms of the effects of fly ash are explained based on a theoretical calculation and phase characterizations in the light of X-ray diffraction (XRD), mercury intrusion porosimetry (MIP) and backscattered electron (BSE) imaging.

\section{EXPERIMENTAL INVESTIGATION}

Materials and mix proportions. Magnesia-Carbon Bricks Plant Co. Ltd., Jinan, China, and was calcined under $1400^{\circ} \mathrm{C}$ for 4 hours and then milled into a powder with a Blain fineness of $3000 \mathrm{~cm}^{2} / \mathrm{g}$ and a maximum particle size of $250 \mu \mathrm{m}$. The KDP and borax were both chemical reagents. The densities of magnesia and KDP are $3.58 \mathrm{~g} / \mathrm{cm}^{3}$ and $2.34 \mathrm{~g} / \mathrm{cm}^{3}$, respectively. In the reference MKPC paste, the magnesiato-phosphate molar ratio $(M / P)$ was 8 , the water-to-cement mass ratio $(W / C)$ was 0.2 (cement here means the combination of magnesia and KDP), and borax was added as a reaction retarder at a level of $4 \%$ by weight of magnesia. In fly ash incorporated pastes, fly ash was used to replace specific volume fractions, i.e. $20 \%, 40 \%$ and $60 \%$, of the solid phases in the reference paste. This replacement strategy keeps the water-to-solid volume ratios constant in all mixtures. However, the water-to-solid mass ratio $(W / S)$ will be changed because the particle density of fly ash is different from that of MKPC. A class F fly ash provided by China Light and Power Co. Ltd., Hong Kong, was used in this work. It has a Blain fineness of $400 \mathrm{~m}^{2} / \mathrm{kg}$ and an average particle density of $2.4 \mathrm{~g} / \mathrm{cm}^{3}$, and it is a low-grade fly ash as its glass content is only $40 \%$. The chemical compositions of the magnesia and fly ash used in this study are given in Table 1, and the mix proportions of the pastes are shown in Table 2. Pastes are denoted as "FA**V", where FA stands for fly ash, ** indicates the fly ash replacement ratio in percentage, and V denotes the volume based replacement. In this way, FA00V denotes the reference paste, and FA40V the fly ash incorporated paste with a fly ash replacement of $40 \%$.

Table 1. Chemical compositions of magnesia and fly ash (\%)

\begin{tabular}{|c|c|c|c|c|c|c|c|c|c|c|c|}
\hline & $\mathrm{MgO}$ & $\mathrm{CaO}$ & $\mathrm{SiO}_{2}$ & $\mathrm{Fe}_{2} \mathrm{O}_{3}$ & $\mathrm{MnO}$ & $\mathrm{P}_{2} \mathrm{O}_{5}$ & $\mathrm{Al}_{2} \mathrm{O}_{3}$ & $\mathrm{SO}_{3}$ & $\mathrm{~K}_{2} \mathrm{O}$ & $\mathrm{TiO}_{2}$ & $\mathrm{LOI}$ \\
\hline Magnesia & 95.10 & 1.60 & 1.94 & 0.68 & 0.13 & 0.24 & 0.31 & - & - & - & - \\
\hline Fly ash & - & 4.63 & 51.58 & 7.45 & 0.15 & - & 27.90 & 1.37 & 1.41 & 1.84 & 3.67 \\
\hline
\end{tabular}


Table 2. Mix proportions of paste mixtures

\begin{tabular}{|c|c|c|c|c|c|c|c|c|c|}
\hline & \multirow{2}{*}{$M / P$} & \multirow{2}{*}{$W / S$} & \multirow{2}{*}{$\begin{array}{l}\text { Borax } \\
\text { (/mag.) }\end{array}$} & \multirow{2}{*}{$\begin{array}{c}\text { FA } \\
\text { (v. } \%)\end{array}$} & \multicolumn{5}{|c|}{ Weights of materials in $\sim 1 \mathrm{~L}$ of paste $(\mathrm{g})$} \\
\hline & & & & & Mag. & KDP & Water & FA & Borax \\
\hline FA00V & \multirow{4}{*}{8} & 0.2 & \multirow{4}{*}{0.04} & 0 & 1325.72 & 532.23 & 371.59 & 0.00 & 53.03 \\
\hline FA20V & & 0.21 & & 20 & 1060.57 & 425.78 & 371.59 & 286.92 & 42.42 \\
\hline FA40V & & 0.22 & & 40 & 795.43 & 319.34 & 371.59 & 573.85 & 31.82 \\
\hline FA60V & & 0.23 & & 60 & 530.29 & 212.89 & 371.59 & 860.77 & 21.21 \\
\hline
\end{tabular}

Sample preparation and tests. For preparation of the paste samples, the powder components were drymixed firstly for 1 minute, which was followed by a mixing with water for 3 minutes, in a vertical-axis planetary mixer. The well-mixed fresh pastes were cast into cubic plastic molds, with the side length of 40 $\mathrm{mm}$, and placed in the ambient environment (cured in air, $25 \pm 1{ }^{\circ} \mathrm{C}, 50 \pm 5 \%$ r.h.). Demolding was carried out after 6 hours, and the cubic specimens were cured under the aforementioned ambient environment until the specific ages (28 days, 90 days and 180 days) when compressive tests were conducted. Compressive strengths were tested according to ASTM C109, on a MTS 815 ROCK Mechanics machine. To evaluate the water resistance of the pastes, cubic specimens were immersed in water at the age of 28 days, and compressive strengths of these immersed specimens were also tested after a specific immersion period and a 2-day equilibrium process in the ambient environment. The considered immersion periods in this study were 60 days and 150 days. The water resistance was characterized by a softening coefficient defined as

$$
R=f_{c}^{w} / f_{c}^{a}
$$

where $f_{c}^{a}$ and $f_{c}^{w}$ are the compressive strengths of a paste as always cured in the ambient environment and ever immersed in water after 28 days, respectively, as tested at the same overall age. The larger this softening coefficient, the better the water resistance of the tested paste.

After compression tests at the age of 180 days, pieces of broken paste were further crushed into smaller pieces with the smallest dimension of 3-5 $\mathrm{mm}$. The pieces were then vacuum-dried to constant weight, and used as samples for pore structure measurement by MIP. A Micromeritics' AutoPore IV 9500 was used for MIP measurements, and the pore structure parameters as well as pore size distribution curves were determined through a data interpretation scheme as recommended by Ma (2014). BSE imaging and EDS (energy dispersive X-ray spectrometer) elemental mapping were employed to investigate the microstructure of pastes, using a Jeol JSM-6390 scanning electron microscope. For BSE image acquisition, the vacuumdried samples for MIP measurement were impregnated with a low viscosity epoxy according to the method used by Barbhuiya et al. (2015), and then carefully polished with sand papers (240, 400, 600, 800 and 1200 grit in order) to achieve a smooth surface following a procedure used for nano-indentation sample preparation (Hu and $\mathrm{Li}$ 2015). Before put in the microscope, the polished surface of a sample was carboncoated. BSE images were taken at a $20 \mathrm{kV}$ accelerating voltage. The dried samples were also pestled, ground and sieved, and powder particles smaller than $80 \mu \mathrm{m}$ were collected as XRD samples. XRD patterns were obtained using a PANalytical X'pert Pro diffractometer with $\mathrm{Cu} \mathrm{K \alpha}$ radiation (1.5406 $\AA$ ). Diffraction patterns were collected between $10^{\circ} \leq 2 \theta \leq 65^{\circ}$ with a step size of $0.033^{\circ}$, at a speed of $12^{\circ} / \mathrm{min}$.

\section{RESULTS AND DISCUSSIONS}

Compressive strength. The compressive strength evolutions of the four pastes (cured in the ambient environment) as listed in Table 2, including the reference MKPC paste and three FA-MKPC (fly ash incorporated MKPC) pastes, are shown in Fig. 1. Each data point in Fig. 1 is an average of three independent 
test results, and corresponding standard deviations are also marked on the figure. It can be seen that the compressive strengths of all pastes increase following the increasing ages. However, when fly ash is incorporated, the increase after 90 days will be very limited. This implies that the hydration reactions in the FA-MKPC paste should have been completed by the age of 90 days. Most probably, KDP is consumed out in the following reaction:

$$
\mathrm{MgO}+\mathrm{KH}_{2} \mathrm{PO}_{4}+5 \mathrm{H}_{2} \mathrm{O} \rightarrow \mathrm{MgKPO}_{4} \cdot 6 \mathrm{H}_{2} \mathrm{O}
$$

Due to the replacement strategy, the incorporation of fly ash didn't change the $M / P$, but it increased the relative amount of water as compared to magnesia and KDP. This could make the complete consumption of KDP occur earlier compared with the case in the reference paste.

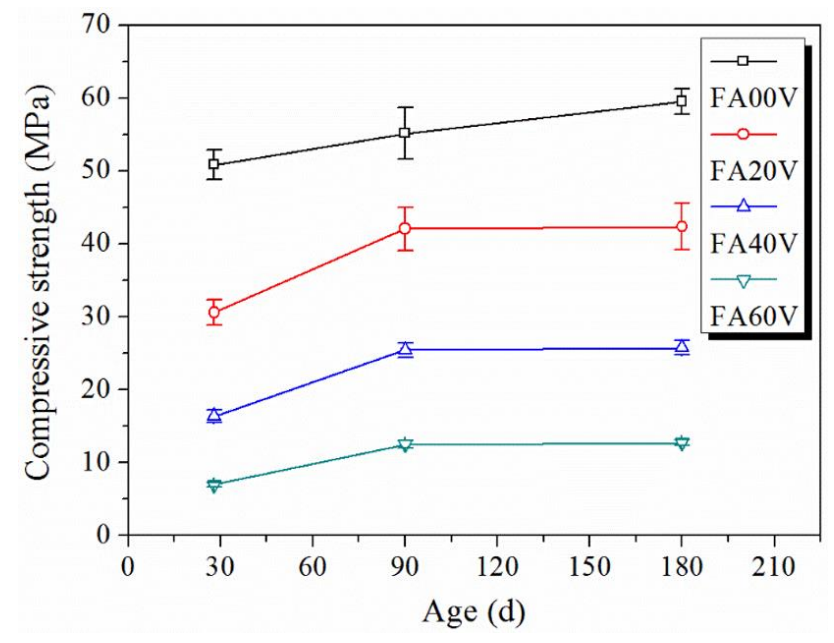

\section{Figure 1. Compressive Strength Evolutions of MKPC and FA-MKPC pastes cured in air}

Figure 1 also indicates that the incorporation of fly ash leads to reductions in compressive strength. The higher the fly ash replacement ratio, the lower the compressive strength. At the age of 180 days, the compressive strengths of the four pastes read 59.5 MPa, 42.43 MPa, 25.74 MPa and 12.75 MPa, showing reductions of $28.7 \%, 56.7 \%$ and $78.6 \%$, respectively, for the FA-MKPC pastes. According to a recent study, compressive strength of MKPC-based materials are determined by a MKP/space ratio (Ma et al. 2016). Herein MKP stands for magnesium potassium phosphate hexahydrate, i.e. the reaction product in Eq. (2) $\mathrm{MgKPO}_{4} \cdot 6 \mathrm{H}_{2} \mathrm{O}$, which is also known as struvite-K. The MKP/space ratio was defined as the ratio between the volume of MKP and the sum of volumes of the reacted magnesia and KDP and the original capillary pores. Mathematically, it can be calculated as

$$
\delta=\frac{V_{M} \cdot \gamma \cdot \alpha_{M} \cdot M / P}{\left(M_{M} \cdot M / P+\eta_{M} \cdot M_{K D P}\right) \cdot W / C+\alpha_{M}\left(V_{M}+V_{K D P}\right) \cdot M / P}
$$

where $\delta$ denotes the MKP/space ratio; $M_{M}$ and $V_{M}$ denote the molar mass and molar volume of magnesia, and their values are $40.3 \mathrm{~g} / \mathrm{mol}$ and $11.25 \mathrm{~cm}^{3} / \mathrm{mol}$, respectively; $M_{K D P}$ and $V_{K D P}$ denote the molar mass and molar volume of KDP, and their values are $136.09 \mathrm{~g} / \mathrm{mol}$ and $58.21 \mathrm{~cm}^{3} / \mathrm{mol}$, respectively; $\alpha_{M}$ is the degree of reaction of magnesia; $\gamma$ indicates the volume of MKP formed when one unit volume of $\mathrm{MgO}$ is reacted, and it equals 12.71 (Ma et al. 2014a); $\eta_{M}$ is the purity of the magnesia. Assuming that KDP has been completely consumed at the age of 180 days in all the pastes, i.e. $\alpha_{K D P}=1$. According to the 
stoichiometry in Eq. (2), the degree of reaction of magnesia $\alpha_{M}=\alpha_{K D P} \times \eta_{M} /(M / P)=1 \times 0.951 / 8=0.119$. Substituting this value into Eq. (3), the MKP/space ratio of the reference paste FA00V at $180 \mathrm{~d}$ can be calculated. Fly ash is generally considered as inert filler in MKPC-based materials (Covill et al. 2011). Assuming that fly ash cannot react with any MKPC components and act purely as a diluent, the MKP/space ratios in the FA-MKPC pastes can also be calculated. The calculated MKP/space ratios are shown in figure 2(a). The relationship between compressive strength and the MKP/space ratio has been empirically established as (Ma et al. 2016)

$$
f_{c}=90.3 \cdot \delta^{3.1}
$$

where $f_{c}$ is the compressive strength. According to equation (4), the compressive strengths of pastes at $\alpha_{K D P}=1$ are predicted, and compared with the strengths obtained at the age of 180 days. This comparison shows that the experimental result agrees well with the prediction for the reference paste. However, when fly ash is incorporated, predictions are always lower than the measured results. As shown in figure 2(b), the measured/predicted "ultimate" strength ratio increases following the increasing fly ash replacement ratios. That is to say, at least one of the two basic assumptions for the prediction must be unreasonable. Since the assumption of $\alpha_{K D P}=1$ is trustable based on figure 1, it must be the inert filler assumption which leads to the underestimation of the compressive strength of fly ash incorporated pastes. It can thus be deduced that fly ash should act as an active filler in the MKPC-based paste system, and it can potentially react with MKPC components to produce some secondary reaction products.
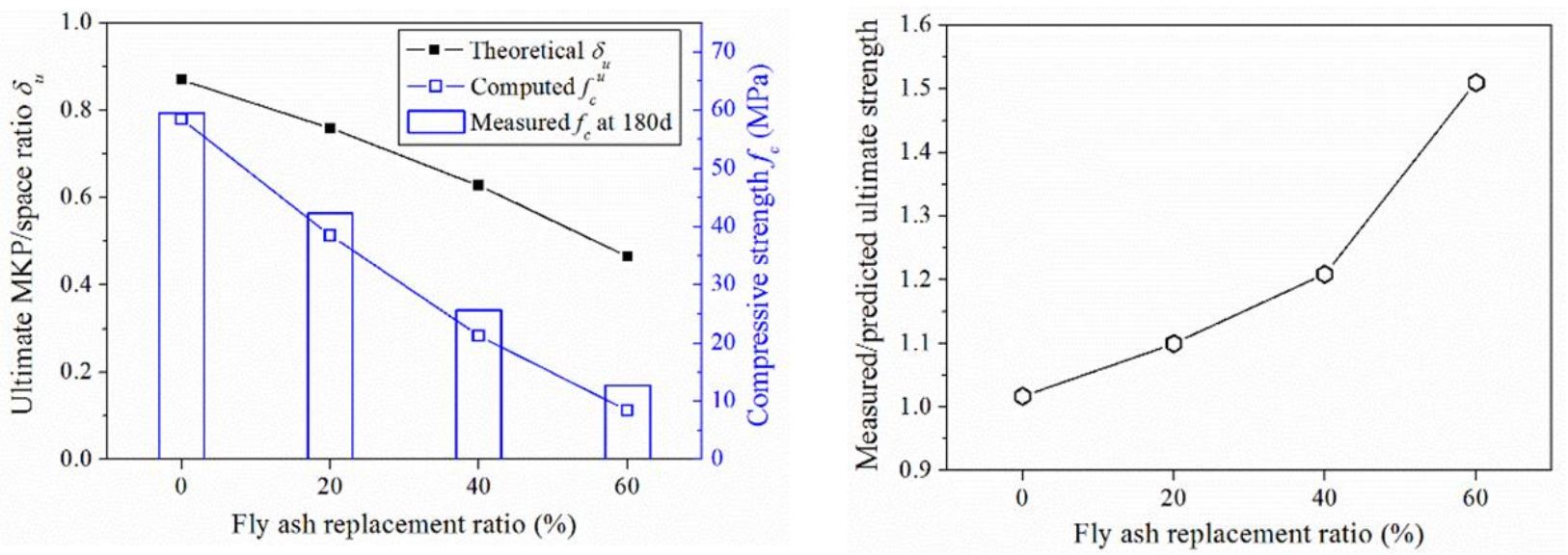

Figure 2. Predictions of the 180-day compressive strengths of pastes: (a) predictions based on MKP/space ratios; (b) comparison with experimental results.

\section{Water resistance}

The compressive strengths of pastes after immersed in water for 2 months and 5 months are shown in figure 3(a). It can be seen that, for the reference MKPC paste, the longer the immersion period, the lower the compressive strength. As a result, the softening coefficient also decreases following the prolonging of the immersion period as shown in figure 3(b), indicating a poor water resistance. When fly ash is incorporated, the compressive strength is reduced first after immersed in water, and then increases. As shown in figure 3(b), the higher the fly ash replacement, the higher the softening coefficient after an immersion period of 5 months. The strength increase of FA-MKPC pastes in water indicates that a reaction involving fly ash may have occurred, which densified the microstructure and enhanced the water resistance. 


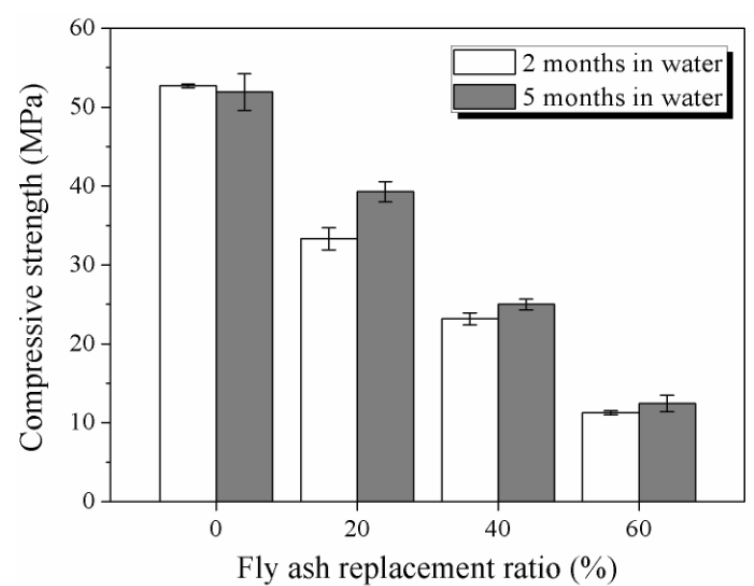

(a)

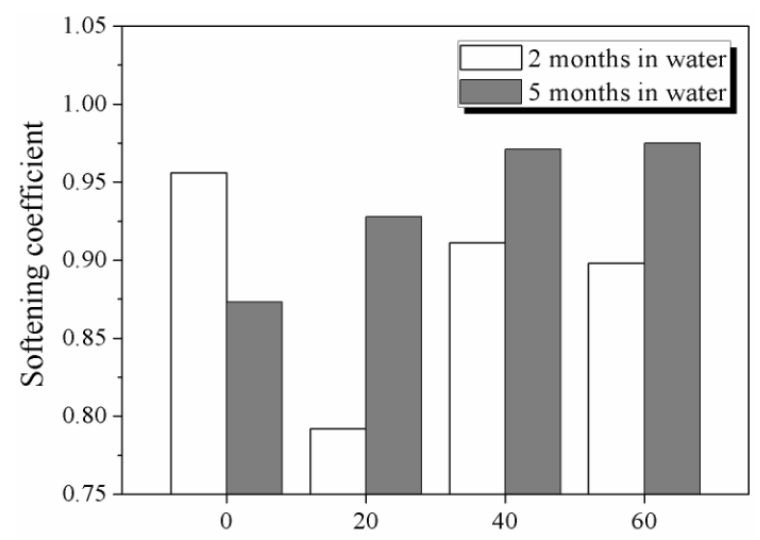

Fly ash replacement ratio (\%)

(b)

Figure 3. Water resistance of the pastes: (a) compressive strengths after immersed in water; (b) softening coefficients.

XRD. XRD patterns of the pastes FA00V and FA40V at the age of 180 days, the raw materials as well as the potential reaction product struvite-K are shown in figure 4 . Through a comparison of these patterns, it is clear that the struvite- $\mathrm{K}$ is the dominant hydration product, at least the dominant crystal product. It also reveals that, at the age of 180 days, no residual KDP can be found in the light of XRD. This finding supports the first assumption made for the compressive strength predictions. Furthermore, in the XRD pattern of FA40V, the small peak of mullite indicates the presence of fly ash, while the lower peaks of $\mathrm{MgO}$ as compared with FA00V imply the less amount of unreacted magnesia. The XRD patterns cannot provide any proof of the potential secondary reaction between fly ash and the MKPC components.

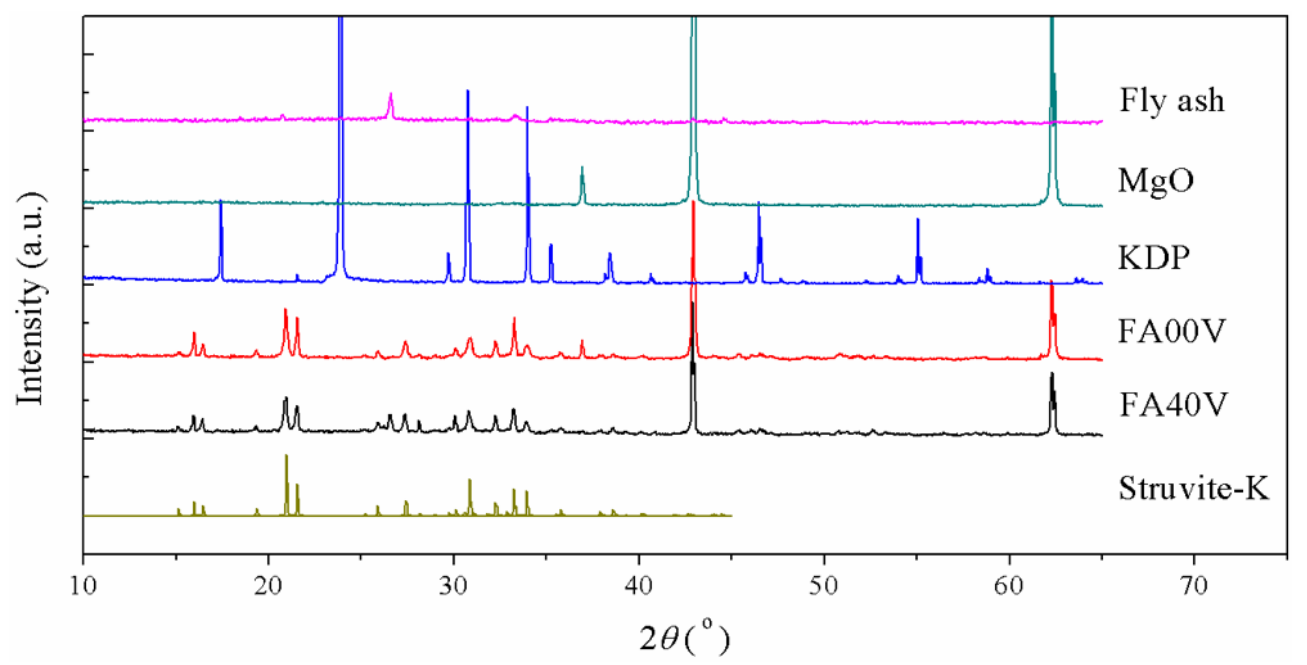

Figure 4. XRD patterns of 180-day pastes, raw materials and the reaction product

MIP. The cumulative porosity curves and log differential pore size distribution curves of pastes cured in air for 180 days are shown in Fig. 5. From Fig. 5(a), the porosities of FA00V, FA20V, FA40V and FA60V can be determined as $4.93 \%, 8.32 \%, 12.95 \%$ and $23.67 \%$, respectively. Through an analysis, it is easy to find that the porosities are inversely proportional to the compressive strengths, which is consistent with the trend revealed in a previous study (Ma et al. 2014b). As shown in Fig. 5(b), the pore size distribution curve of FA00V follows a quasi-normal distribution. However, when fly ash is incorporated, the curves follow multimodal distributions. Since the softening of the pastes could be attributed to the leaching of struvite-K, 
the much finer pore structures (higher small-pore volume fractions) of the FA-MKPC pastes may be partially responsible for their better water resistance, apart from the potential formation of secondary reaction products.

(a)

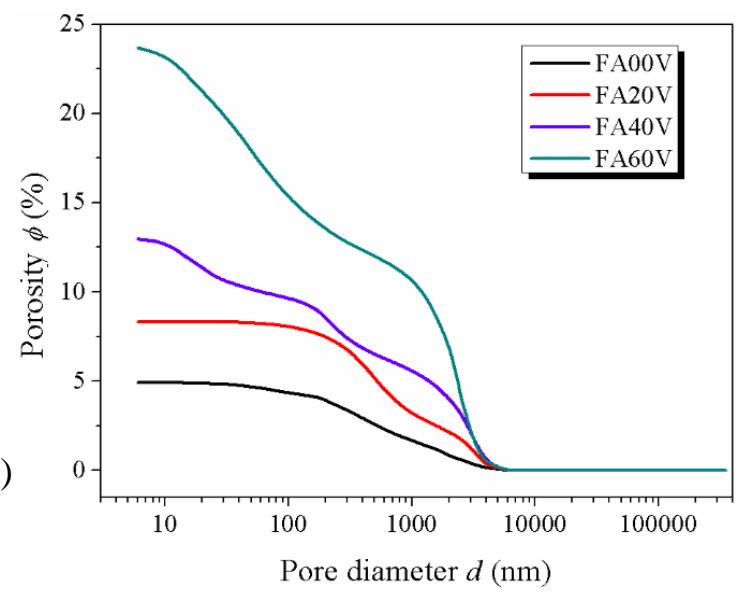

(b)

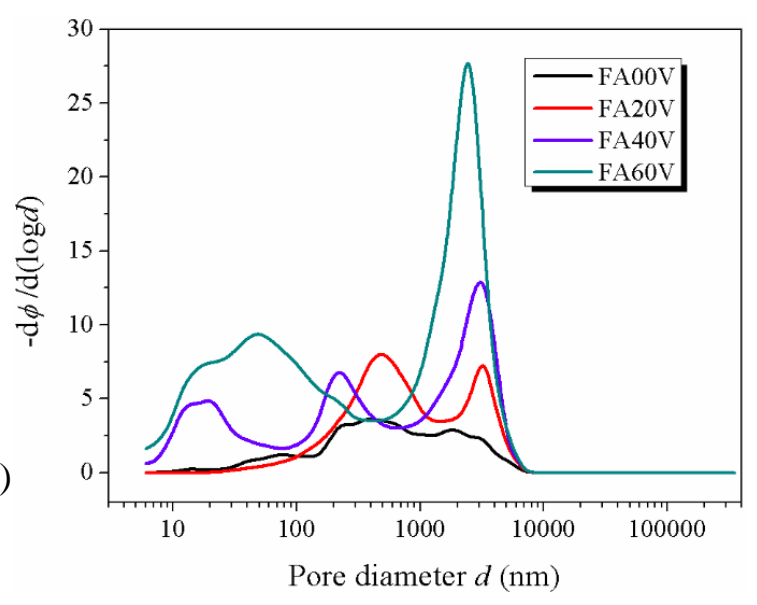

Figure 5. MIP results of 180-day pastes: (a) cumulative porosity curves; (b) log differential pore size distribution curves.

BSE imaging and elementary mapping. BSE images and elementary mappings (in terms of $\mathrm{Mg}, \mathrm{K}, \mathrm{Ca}$, $\mathrm{Si}$ and $\mathrm{Al}$ ) of FA00V and FA40V are shown in Fig. 6. Fig. 6(a) shows the case of FA00V, in which the unreacted magnesia particles can be clearly seen in the BSE image and confirmed by the Mg mapping. The $\mathrm{K}$ mapping indicates the existence of struvite- $\mathrm{K}$ in the complementary areas. From the $\mathrm{Ca}$ and Si mappings, it can be concluded that the magnesia particles may be ingrained with calcium silicate impurities, which is consistent with the chemical composition of magnesia as shown in Table 1. Fig. 6(a) also shows that the struvite-K particles appear with a laminar habit in the polished section, and gaps (pores) exist among the struvite-K particles. In the reaction process of a MKPC paste, the acid-base reaction can first lead to formation of a gel, and the gel can then thicken progressively and finally crystalize around the unreacted magnesia particles into an inter-connected crystal lattice (Wagh and Jeong 2003). The resultant crystal lattice is said to be a monolithic ceramic at a relatively large length-scale, but it shows a complex morphology at a shorter length-scale (e.g. at the micro-scale). On the one hand, the struvite-K crystal particles at the micro-scale have been reported to be in rod-like, prismatic, laminar or other irregular shapes in MKPC-based materials (Qiao et al. 2010; Ding et al. 2012). An assembly of poorly connected irregular particles may show a morphology as seen in Fig. 6. On the other hand, before being dried, the continuous binder phase in a MKPC paste could be composed of struvite-K particles and a gel. The drying process 
could lead to gel thickening, and the resultant crystallization of struvite- $K$ could make the struvite- $K$ particles partially connected, leaving gaps between neighboring particles.
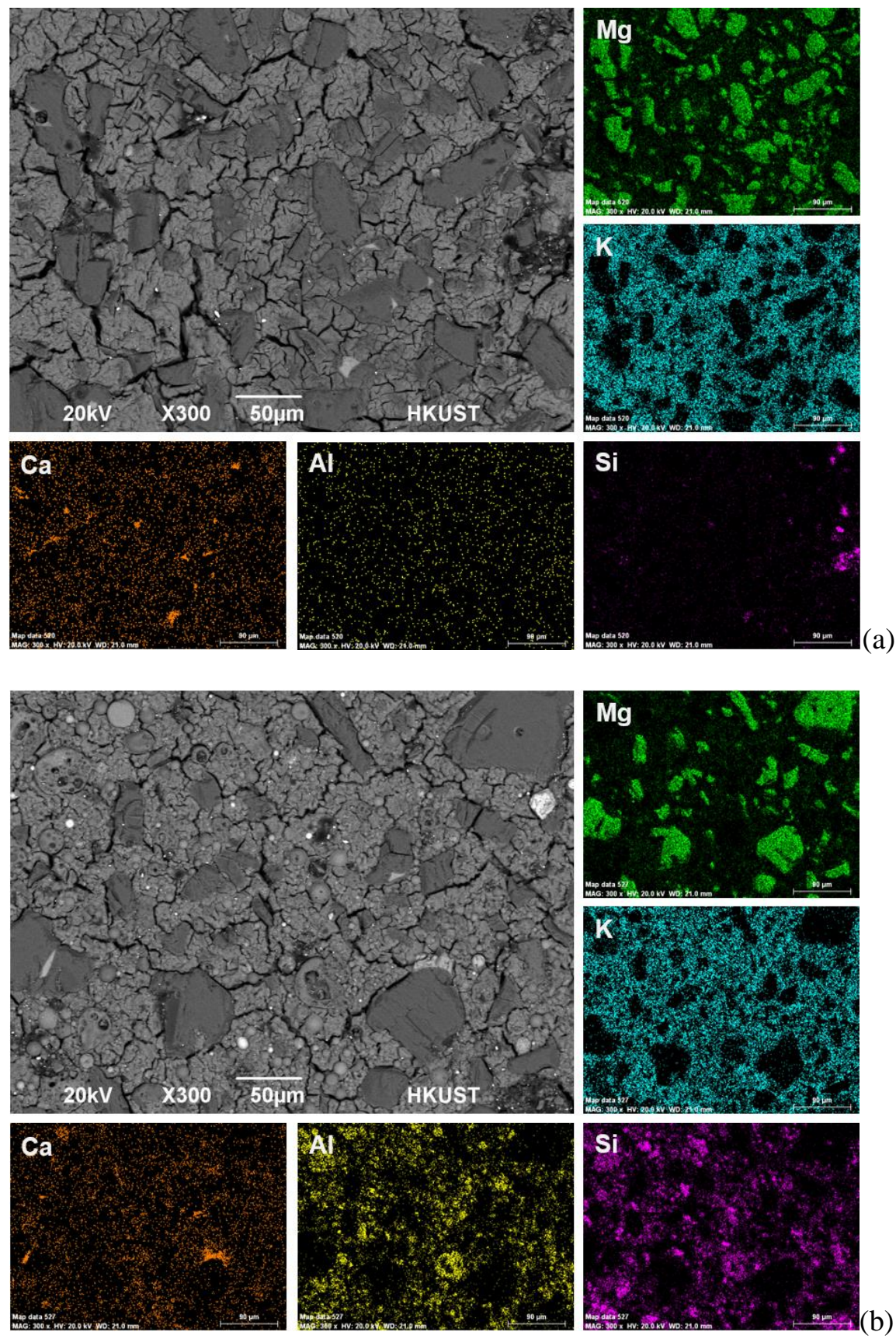

Figure 6. Backscattered electron micrograph and elemental maps of pastes: (a) FA00V; (b) FA40V.

The microstructure of FA40V is shown in Fig. 6(b). It shows a microstructure very similar to that of FA00V, except for a lower volume fraction of unreacted magnesia grains and the presence of fly ash particles. From the $\mathrm{Al}$ and Si mappings, it can be seen that these two elements are not restrained in the original areas of fly ash particles, but have been incorporated in the binding matrix of the FA-MKPC paste. According to Gardner et al. (2015), this can be considered as a proof of the dissolution of the aluminosilicate glassy 
phases in fly ash, but not a proof of the formation of any secondary reaction products. Fig. 6(b) shows a poorer continuity of the formed struvite-K matrix due to the disturbing of fly ash particles, which should be responsible for the lower compressive strength.

Discussion on synergy mechanism. Most researchers tend to believe that it is the aluminosilicate glassy fraction in fly ash which acts as the active component and reacts with MKPC (Gardner et al. 2015; Covill et al. 2011). However, to the authors' knowledge, no one has identified the secondary reaction product, or even obtained any direct evidence of the said secondary reaction. In this study, it is deduced from compressive strength analysis and water resistance measurement that a secondary reaction between fly ash and MKPC raw materials or hydration product should have taken place, but no direct evidence has been found to support this deduction. Unpublished FTIR data has neither found direct proof of the formation of any secondary product. Even though more advanced characterization method, high field nuclear magnetic resonance, has been employed, Gardner et al. (2015) has proven nothing more than the potential formation of potassium-aluminosilicate phase. In our view, the synergetic interaction between MKPC and fly ash may be largely attributed to the reaction between other components, most probably a reaction between $\mathrm{CaO}$ and KDP. Actually, fly ash has been used for phosphate removal from water, and the phosphate removal efficiency are directly proportional to its $\mathrm{CaO}$ content (Mikendová et al. 2010). It is thus reasonable to believe that $\mathrm{CaO}$ plays a key role in phosphate removal by forming $\mathrm{Ca}_{3}(\mathrm{PO} 4)_{2}$. Furthermore, it has been found that high-Ca fly ash used as replacement material in MKPC paste can achieve a higher compressive strength than a low-Ca fly ash at the same replacement ratio. As reported by Gardner et al. (2015), a ground granulated blast-furnace slag, which has a much higher $\mathrm{CaO}$ content than fly ash, improve the compressive strength of a MKPC paste significantly, while a class F fly ash only improved the strength moderately.

\section{CONCLUSION}

The following general conclusions can be drawn from the study provided in the paper:

- Low-grade fly ash can be used as supplementary cementitious material in MKPC based material; although it reduces the compressive strength, it can make the material properties more stable when subject to water immersion condition.

- Struvite-K is the dominant reaction product in both MKPC and FA-MKPC pastes.

- As deduced from experimental data analysis, a secondary reaction involving fly ash should be responsible for the achieved properties of FA-MKPC pastes, but the reaction products have not been identified so far.

- Compressive strengths of (FA-)MKPC pastes are inversely proportional to their porosities.

Note that the conclusions are drawn on the basis of constant $W / S$ and volume-based replacement of MKPC solid components. They don't hold when fluidity is taken as the control parameter and different $W / C$ ratios are used, and when weight-based replacement of MPC components or $\mathrm{MgO}$ is adopted during mixture design.

\section{ACKNOWLEDGEMENT}

Financial support from the Hong Kong Research Grants Council under 615810 and from Missouri S\&T new faculty start-up funds is gratefully acknowledged.

\section{REFERENCES}

ASCE. (2013). “2013 report card for America's infrastructure.” http://www.infrastructurereportcard.org/ (Dec. 17, 2015)

ASTM C 109/C 109M. "Standard Test Method for Compressive Strength of Hydraulic Cement Mortars (Using 2-in. or [50-mm] Cube Specimens)." ASTM International, West Conshohocken, PA, 9 pages. 
Barbhuiya, S., Chow, P., and Memon, S. (2015). "Microstructure, hydration and nanomechanical properties of concrete containing metakaolin." Construction and Building Materials, 95, 696-702.

Covill, A., Hyatt, N.C., Hill, J., and Collier, N.C. (2011). "Development of magnesium phosphate cements for encapsulation of radioactive waste." Advances in Applied Ceramics, 110, 151-156.

Ding, Z., Dong, B., Xing, F., Han, N., and Li, Z. (2012). "Cementing mechanism of potassium phosphate based magnesium phosphate cement." Ceramics International, 38, 6281-6288.

Ding, Z., and Li, Z. (2005). "High-early-strength magnesium phosphate cement with fly ash." ACI Materials Journal, 102(6), 375-381.

Formosa, J., Chimenos, J. M., Lacasta, A. M., and Niubo, M. (2012). "Interaction between low-grade magnesium oxide and boric acid in chemically bonded phosphate ceramics formulation." Ceramics International, 38, 2483-2493.

Gardner, L. J., Bernal, S. A., Walling, S. A., Corkhill, C. L., Provis, J. L., and Hyatt, N. C. (2015). "Characterisation of magnesium potassium phosphate cements blended with fly ash and ground granulated blast furnace slag." Cement and Concrete Research, 74, 78-87.

$\mathrm{Hu}, \mathrm{C}$., and Li, Z. (2015). "Property investigation of individual phases in cementitious composites containing silica fume and fly ash." Cement \& Concrete Composites, 57, 17-26.

Juenger M. C., Winnefeld F., Provis J. L. and Ideker J. H. (2011). "Advances in alternative cementitious binders." Cement and Concrete Research, 41, 1232-1243.

Ma, H. (2014). "Mercury intrusion porosimetry in concrete technology: Tips of measurement, pore structure parameter acquisition and application." Journal of Porous Materials, 21, 207-215.

Ma, H., Xu, B., and Li, Z. (2014a). "Magnesium potassium phosphate cement paste: Degree of reaction, porosity and pore structure." Cement and Concrete Research, 65, 96-104.

Ma, H., Xu, B., and Li, Z. (2016). "Does an optimal magnesia-to-phosphate ratio exist in magnesium potassium phosphate cement based materials?" Cement \& Concrete Composite, submitted.

Ma, H., Xu, B., Liu, J., Pei, H., and Li, Z. (2014b). "Effects of water content, magnesia-to-phosphate molar ratio and age on pore structure, strength and permeability of magnesium potassium phosphate cement paste." Materials \& Design, 64, 497-502.

Mikendová, B., Thomas, J., and Daněk, T. (2010). "Phosphorus removal from water using fly ash and modified fly ash-comparison of X-ray fluorescence spectrometry and standard spectrophotometric methods." GeoScience Engineering, LVI, 22-31.

Provis, J. L., Harrex, R. M., Bernal, S. A., Duxson, P., and van Deventer, J. S. (2012). "Dilatometry of geopolymers as a means of selecting desirable fly ash sourses." Journal of Non-Crystalline Solids, 358, 1930-1937.

Qiao, F., Chau, C., and Li, Z. (2010). "Property evaluation of magnesium phosphate cement mortar as patch repair material." Construction and Building Materials, 24(5), 695-700.

Seehra, S. S., Gupta, S., and Kumar, S. (1993). "Rapid setting magnesium phosphate cement for quick repair of concrete pavements - characterisation and durability aspects." Cement and Concrete Research, 23(2), 254-266.

Wagh, A. S., and Jeong, S. Y. (2003). "Chemically bonded phosphate ceramics: I, a dissolution model of formation." Journal of the American Ceramic Society, 86, 1838-1844.

Yang, Q., Zhu, B., Zhang, S., and Wu, X. (2000). "Properties and applications of magnesia-phosphate cement mortar for rapid repair of concrete." Cement and Concrete Research, 30(11), 1807-1813. 